\title{
LA REFORMA DEL EsTAdo MEXICANO DESDE SU PERIFERIA
}

\author{
María del Carmen García Aguilar \\ Alain Basail Rodríguez
}

\section{Introducción}

$\mathrm{E}$ neste artículo se intentan analizar los significados que para la sociedad chiapaneca tiene el debate sobre la reforma del Estado mexicano. Significados que al apuntalar los sentidos de las prácticas políticas reales, permiten esbozar un marco analítico presente y prospectivo que dé cuenta de las capacidades materiales y emotivas de los actores de la sociedad local para la construcción de un proyecto de cambio social y político con un sentido democrático y por la vía de las instituciones.

En la sociedad local, y en sus organizaciones, priva una concepción realista de la reforma del Estado. El argumento es sólido: la reforma del Estado se ha expresado en cambios institucionales orientados a generar las condiciones para que éste desempeñe eficazmente sus funciones sustantivas en atención a las exigencias de la economía neoliberal. Sus impactos se manifiestan en la grave desprotección social, la acentuada fragmentación del tejido social y los problemas de gobernabilidad que, por la misma lógica de las reformas ya instituidas, tienden a acrecentarse. Esta percepción constatable en los espacios

María del Carmen García Aguilar y Alain Basail Rodríguez, CESMECA-UNICACH sociales periféricos, no sólo propicia un sentimiento antiestatista, también la búsqueda de canales de representación alternativos que, por la fuerza que hoy están cobrando, representan un enérgico cuestionamiento a los cimientos tradicionales del Estado liberal democrático.

Desde las periferias, una agenda de reforma del Estado mexicano considera el plano de los derechos humanos y las libertades públicas, de la representación política y de la democracia participativa, así como exigencias sociales para replantear la lógica y el sentido de las estructuras institucionales que definen el marco normativo de la relación entre el poder federal y los estados, y el de las relaciones entre gobernantes y gobernados, particularmente la estructura de la toma de decisiones gubernativas.

En tanto la reforma del Estado no es un hecho acabado, sino un proceso que como tal prefigura un marco de acción y un discurso político dinámico sujeto a múltiples posibilidades, nuestra reflexión pretende considerar algunos elementos polémicos, en cuestión: las lecciones de la alternancia en México y en Chiapas, el papel de los actores políticos chiapanecos, las dinámicas de poder local, las formas de relacionarse el gobierno estatal con la sociedad, las exigencias 
planteadas al pacto federal y los desafíos de construcción sociopolítica —ciudadanía, gobernabilidad y nuevo federalismo-. Así, desde lo local y lo periférico, se busca contribuir al esfuerzo de pensar y actuar en la construcción de un modelo de Estado que, sobre la base de la equidad, recupere la legitimidad de las instituciones y los nexos entre la sociedad y el sistema político. Convencer a la sociedad local y a sus actores, que en tanto ciudadanos tienen los derechos y la capacidad real para reorientar la dirección que hoy domina el campo de las reformas del Estado, así como que la democracia política constituye la principal arma para lograr los cambios que la sociedad exige; no es una tarea menor, sin embargo es una tarea urgente, pues se corre el riesgo de hacer de la democracia política otro "mito genial", ahora del siglo xxi, o un "cascarón vacío” (Castells, 1999: 387).

\section{La reforma del Estado. Una síntesis crítica}

Como concepto histórico y procesual, el de reforma del Estado indica que toda transformación de los modelos de relación entre la sociedad y el Estado ha implicado una reforma de éste. Así, en el siglo xx se registra el impulso y desarrollo de un Estado-modelo keynesiano y, después, su desplazamiento por un Estado-modelo neoliberal, trayendo consigo profundas reformas tanto en las reglas de uso y distribución del poder como en las formas de aplicación y expansión de sus políticas públicas (Pérez Fernández, 2001: 241). $\mathrm{Al}$ acotar la reforma del Estado en México, Alberto Aziz propuso entenderla como un proceso de reacomodo del Estado como poder y como aparato, para la resolución de dos factores básicos: las condiciones de gobernabilidad de un régimen político que empezó a ser obsoleto y la readecuación del desarrollo económico a las nuevas condiciones internacionales (1991: 77-78).
Más recientemente, César Cansino (2004) reconoció que la actual reforma del Estado no es de corte coyuntural para adecuarlo a las nuevas necesidades globales del mercado y el comercio internacional, sino una reforma política y normativa, una reforma para refundar al Estado mexicano en su conjunto, sobre nuevas bases claramente democráticas. Es un paso lógico y necesario en el proceso de transición democrática subsecuente a la alternancia en el poder presidencial que se registró en 2000 , tras algunos casos en municipios y entidades sobre todo del norte y el centro del país. Se encamina, dice, a crear una democracia constitucional, esto es, aspira a hacer compatible la estructura constitucional con la democracia, cuya agenda temática centraliza las dimensiones de los derechos y garantías, el equilibrio de los poderes de la unión y los de la federación, el federalismo, la estructura político-electoral, las obligaciones económicas del Estado y los propios procedimientos de reforma constitucional (p. 58).

Este marco conceptual nos permite reconocer la naturaleza sistémica de la reforma del Estado y, también, su trayectoria signada por el conflicto, la incertidumbre y la posibilidad de cambio. La primera gran reforma del Estado, hace más de dos décadas, implicó la supresión del modelo benefactor, instituyéndose como tendencia el del Estado neoliberal. La justificación primaria de este cambio fue de naturaleza económica: la crisis fiscal, el endeudamiento del país y sus impactos de crispación social, así como las directrices de la economía mundial que mostraban la inadecuación del Estado interventor. La configuración del Estado sustituto, si bien ha sido una tarea modulada con un estilo tecnocrático a tono con los organismos financieros internacionales y el gran capital internacional y nacional, ha terminado por involucrar, por sus agresivos impactos, a los distintos actores políticos y sociales del país, definiendo un escenario de ajustes en el que son visibles las tensiones que de no resolverse o 
no administrarse ponen en riesgo la estabilidad misma del Estado y del país, o sea, su propia gobernabilidad.

En efecto, frente a los impactos sociales de la primera generación de reformas que se tradujeron en el repliegue del Estado mexicano de la economía y los mercados, fueron notables tanto la introducción de ajustes macroeconómicos por los propios diseñadores del Estado neoliberal y la ausencia de las reformas políticas que hicieran posible la reforma estructural (Torres, 1997; Flores Olea, 1995), como la configuración de fuerzas políticas, académicas e intelectuales y sociales nacionales que, en distintos grados, han interpelado el carácter depredador de las reformas económicas, exigido la anulación o la aplicación gradual de las mismas y subrayado cómo se había sustraído uno de los soportes más sensibles de la reforma del Estado: la democratización del régimen político mexicano. Hay, pues, un esfuerzo desde la sociedad civil y los sectores académicos por contribuir al diseño de un Estado democrático, recuperando la crítica en torno a los impactos negativos que sobre la democracia tienen las propias políticas de reformas económicas del Estado neoliberal.

En resumen, la reforma del Estado no es un hecho acabado, sino un proceso que como tal prefigura un marco de acción y de discurso político signado por intereses en conflicto y negociaciones que no siempre culminan con el modelaje inicialmente ideado. A este respecto, recordemos la trayectoria y los resultados de los acuerdos y compromisos nacionales sobre la reforma del Estado, particularmente el Acuerdo Político Nacional (1995), suscrito por los partidos políticos, en el que se establecieron compromisos sustantivos para el cambio democrático en un marco institucional de pluralidad, ${ }^{1}$ y el Diálogo Nacional para la Reforma del Estado, en el que el Congreso estableció la agenda y las bases del Diálogo para las Reformas políticas, legales, económicas y sociales. ${ }^{2}$ También, deben mencionarse los compromisos que en campaña y en la toma de posición hizo Vicente Fox, ${ }^{3}$ en el ámbito de la reforma del Estado, creándose de manera inmediata la Comisión de Estudios para la Reforma del Estado, CERE, presidida por Porfirio Muñoz Ledo, de la que derivaron propuestas consensuadas pero que a cinco años del sexenio no se han llevado a la práctica. ${ }^{4}$

Además deben considerarse, como producto de la voluntad de cambio democrático de la sociedad nacional, las reformas en su vertiente electoral: la de agosto de 1990, que derivó en la creación del Código Federal de Instituciones y Procedimiento Electorales, COFIPE; el Instituto Federal Electoral, IFE; el Tribunal Federal Electoral y la nueva credencial de elector en agosto de 1990; la de agosto de 1993, donde se reformaron 18 artículos constitucionales y se registraron más de 100 modificaciones al COFIPE; las de 1994 y 1996, que culminaron con la aceptación de observadores electorales extranjeros; la ciudadanización del IFE, el aumento del financiamiento público de los partidos en una proporción de nueve a uno respecto al privado, la redistritación de los 300 distritos de mayoría que se crearon desde la reforma de 1997, y un nuevo reparto de los tiempos de los partidos a los medios masivos (Aziz, 2003).

No obstante, como decíamos, el soporte más sensible que justifica la reforma del Estado mexicano es la consolidación del régimen democrático que exige el rediseño del entramado político y jurídico-institucional. La tarea ya no es sólo de los políticos. De alguna manera, pese a la inercia de esta última administración, el trabajo realizado por la CERE constituye un avance significativo para, desde distintos frentes, apuntalar la construcción de una democracia constitucional. Los seis grandes temas que sintetizan la realidad nacional y su agenda política son: derechos humanos y libertades políticas; objetivos económicos y sociales del Estado; representación política y democracia participativa; formas de gobierno y organización de los poderes públicos; federalismo, 
descentralización y autonomías; por último constitución y globalidad. Estos temas definen el enorme desafío que para la sociedad implica articular y sintonizar la estructura constitucional con la democracia (Muñoz Ledo, 2004).

\section{La reforma del Estado desde la periferia chiapaneca}

En Chiapas el tema de la reforma del Estado se ha excluido tanto de la agenda del gobierno estatal y de los gobiernos municipales como del debate político entre los actores políticos y sociales. No fue hasta enero de 1994, con la irrupción neozapatista, cuando el tema se dibujó en el escenario político de la entidad. Sin embargo, la coyuntura de ese año y el curso de las definiciones políticas moduladas en buena medida por el gobierno federal propiciaron la fractura de la sociedad digamos que en dos grandes frentes: por un lado, quienes aprobaron la legitimidad del Diálogo Nacional para la reforma del Estado mexicano como el espacio para debatir y llegar a resoluciones sobre la amplia agenda que entraña la reforma estatal; y, por otro, quienes, en torno al EZLN, se posicionaron en el marco de los llamados Acuerdos de San Andrés con una agenda que intentó incorporar el tema de la reforma del Estado insistiendo en reivindicar los derechos indígenas y la declaración del carácter multicultural del mismo. Entre ambos extremos, se encontraba un amplio sector de la población más interesado en la resolución inmediata de problemas políticos, económicos y sociales particulares (García, Leyva y Burguete, 1998).

En términos generales, ha sido nula la participación de los actores políticos chiapanecos, gobiernos, legislatura local y partidos políticos, en la construcción de agendas, debates y propuestas en materia de reforma del Estado. La coyuntura política abierta por el neozapatismo y los recurrentes cambios en la gobernatura estatal propiciaron una dinámica de confrontación entre los poderes ejecutivo y legislativo, entre partidos políticos y entre éstos y el EZLN y la sociedad civil, que prácticamente han cancelado las posibilidades de una agenda política común que pretendiera impulsar transformaciones de largo alcance. Incluso, puede afirmarse que muchos de los resultados en el campo de las reformas constitucionales en el ámbito del municipio o el electoral, la legislatura local chiapaneca las ha aprobado sin una revisión crítica o propositiva, como ocurrió con la reforma al artículo 115 constitucional federal, instituida en 1999 (véase Rodríguez, 2004).

Otro es el escenario que se presentó con el EZLN y las fuerzas y actores sociales articulados a éste. En el curso de 1994 tres hechos definieron el comportamiento político del EZLN: inicialmente privilegió una postura radical, sustentada en una estrategia de deslegitimación del Estado y sus instituciones de gobierno; después optó por incorporarse a los procesos electorales bajo un objetivo y una estrategia propia; finalmente asumió la decisión de romper el cerco militar y tomar posiciones en 38 municipios declarándolos municipios y territorios rebeldes.

Sin embargo, se dieron dos eventos que posibilitaban la incorporación del EZLN al debate político nacional. El primero fue la creación de la Comisión de Concordia y Pacificación, COCOPA, integrada por los partidos políticos representados en el poder Legislativo y, el segundo, la creación del Acuerdo Político Nacional y el Diálogo Nacional para la Reforma del Estado. La incorporación del EZLN al debate nacional de la reforma del Estado no se dio en el marco de los dos acuerdos instituidos en el ámbito nacional para tal fin. Y es que desde un principio la posición de la parte gubernamental era clara en el sentido de deslindar la participación del EZLN en el debate de la reforma del Estado, aunque la COCOPA opinó lo contrario e, incluso, dio a conocer el documento "Reiniciar el diálogo nacional para reforma del 
Estado: una exigencia nacional' en agosto de 1995. Este documento permitió, en septiembre del mismo año, la firma de un comunicado conjunto entre la COCOPA y el EZLN, en donde la primera se comprometía impulsar la participación del segundo en el diálogo nacional para la reforma del Estado. ${ }^{5}$ A pesar de todo al EZLN, cuya postura logró simpatías y rechazos abiertos, se le marginó.

En el primer documento, la COCOPA define su posición en torno a dos problemas de origen de la reforma del Estado, a saber: la exclusión de las organizaciones de la sociedad civil y la restricción en la demarcación del campo de éstas a las estructuras de las instituciones estatales y al sistema electoral y de partidos. De entrada, hay una objeción a la exclusividad de la democracia representativa, y una propuesta a incluir la democracia directa como el referéndum y el plebiscito. En el punto sobre Democracia Integral plantea que la construcción de la democracia debe rebasar las dimensiones estrictamente electorales y partidarias, lo que exige ampliar las formas de participación política y los espacios de organización ciudadana y de los núcleos populares, mediante mecanismos de democracia directa y participativa, a través de organizaciones que permitan a la sociedad civil actuar comprometidamente en la definición y control de las políticas públicas.

Sin duda, el EZLN abrió un tema crucial que es hoy parte sustantiva de las propuestas de reforma del Estado. Nos referimos a las relaciones del Estado con los pueblos indios y la defensa de sus derechos y universo sociocultural. Como se sabe, hasta el final del sexenio zedillista los Acuerdos de San Andrés y la versión jurídica de la COCOPA no habían llegado al Congreso, aunque para el gobierno federal las respuestas ya estaban en marcha pues había ordenado a su homólogo estatal la instrumentación de cambios a la Constitución del estado de Chiapas, con lo que creía se estaban cumpliendo los compromisos subscritos en San
Andrés. En 2000 se exigió que como iniciativa del Ejecutivo se enviara al Congreso para su aprobación la versión jurídica de la COCOPA. Sobre los resultado de esta iniciativa podemos decir que, con excepción de la bancada priísta, se asumió ilegítima por el resto de las fracciones parlamentarias del Congreso local, trayendo consigo el descrédito de las instituciones.

Para el gobierno zedillista, los Acuerdos de San Andrés se tradujeron en respuestas institucionales circunscritas al territorio chiapaneco. En efecto, como respuesta a dichos compromisos se realizaron modificaciones y adiciones a la Constitución de Chiapas, entre las que destacan: la creación de la Defensoría de Oficio Indígena, el Centro Estatal de Lengua, Arte y Literatura Indígena, la Visitaduría General de la Comisión Estatal de Derechos Humanos y, por parte de la Comisión Nacional de Derechos Humanos, la Cuarta Visitaduría General para Asuntos Indígenas. Posteriormente, anunciados como un avance en materia de justicia indígena, se crean los Juzgados de Paz y Conciliación en los municipios con población mayoritariamente indígena ("1995-1997: Chiapas, esfuerzo compartido", Cuarto Poder, enero 7, 1998). ${ }^{6}$ Este paquete de respuestas concluyó con la aprobación, por parte del Congreso estatal, de un decreto de remunicipalización que no sólo implicó la creación de siete nuevas municipalidades, la mayoría alejadas de la zona de conflicto, sino un alto costo político, pues al rechazo abierto del EzLN se sumó el de los partidos políticos de oposición y de amplios sectores de la sociedad local y nacional.

Excluido el EZLN del debate nacional sobre reforma del Estado, y sin ningún avance en materia de derecho y cultura indígena, no había por qué esperar del EZLN y las organizaciones sociales simpatizantes una visión positiva sobre la reforma del Estado mexicano, aún cuando con una visión crítica y propositiva estaba siendo impulsada por sectores importantes de la sociedad nacional. Del Ejecutivo de Chiapas, en su mayoría en 
calidad de sustitutos e interinos desde 1993 y colocados directamente por el Ejecutivo federal, tampoco había que esperar una preocupación genuina que contemplara una agenda con temáticas de la reforma del Estado, por lo que se afectó el campo de las gobernaturas. El centralismo en la designación los hizo proclives al estricto cumplimiento de las políticas del gobierno federal.

\section{Los claroscuros de la reforma del Estado}

Sin dejar de reconocer que el contexto sociopolítico de los últimos años se ha caracterizado por la virulencia de la crisis económica, el desorden social, la ingobernabilidad y la falta de consenso mínimo entre los actores políticos y sociales para trazar una ruta de futuro común, los claroscuros de la reforma del Estado en Chiapas hacen referencia fundamentalmente a la continuidad de dinámicas autoritarias y centralistas y a la ausencia de actores políticos para encararlas con sentido democrático. También, a los numerosos grupos de la sociedad civil, simpatizantes o no del EZLN, que han privilegiado una estrategia de deslegitimación del Estado y sus instituciones gubernativas, e impulsado intensas convocatorias y llamados a revitalizar el poder de la sociedad civil para erigirse en actor directo de las transformaciones que demanda la sociedad nacional.

Sin embargo, la reforma del Estado es, del mismo modo, una oportunidad histórica de la sociedad civil para redefinir el régimen político mexicano desde la periferia. Los vientos de una época de cambios posibilitan cierta lectura crítica y renovada del campo más sensible de la reforma del Estado mexicano: el de las relaciones entre el poder federal y los estados, cuestión básica para hablar de un Estado Federal Democrático. La construcción de una democracia federativa, cuya ventaja funcional es hoy su constante innovación, exige retos prácticos ante los desafíos de la globalización y el pluralismo cultural. Implica desde el campo de la política y el derecho, particularmente desde la teoría neoconstitucionalista, superar la búsqueda de valores absolutos propiciando nuevas estructuras jurídico-constitucionales conciliadas con el plano axiológico para potenciar prácticas políticas efectivas en la transición y consolidación del sistema democrático (Serrano, 2004).

La dualidad en la división de poderes del Estado federal $^{7}$ ofrece retos que la reforma del Estado mexicano debe encarar. Como señala Serrano (2004), la idea de soberanía, tradicionalmente entendida como la supremacía en la esfera estatal interna y la independencia hacia el exterior, ya no guarda correspondencia con el pluralismo político y social interno; tampoco, con la conciencia de la diferencia hoy generalizada, que exige no sólo preservar y promover sus propias identidades y culturas de manera privada, sino el reconocimiento explícito en las reglas del juego democrático (Requejo, 2002: 24). En este tenor, desde la periferia de México, un país pluriétnico de profundas asimetrías regionales y sociales, se exige, en el marco normativo democrático: a) el replanteamiento del pacto federal considerando el desfase en los desarrollos regionales y el papel de las políticas públicas en la constitución y modulación de esas diferencias; b) el replanteamiento de las relaciones interétnicas, un hecho que cuestiona formas tradicionales de organización y ejercicio del poder del Estado y obliga a formular una serie de reformas operativas e institucionales.

El análisis contemporáneo sobre el federalismo está no sólo replanteando las formas de pensar la democracia en los Estados federados, también la manera de recuperar las virtudes del sistema federal en su tarea de fortalecer la democracia. Este ejercicio culmina en la propuesta del federalismo como pluralismo constitucional defendida por Serrano (2004) o la del federalismo pluralista de Miquel Caminal (2002). De acuerdo con Serrano, la tradicional idea de soberanía ya no puede reconocerse como realidad política 
operante. Recuperando el enfoque del neoconstitucionalismo cita a Zagrebelsky, uno de sus exponentes:

Desde finales del siglo pasado actúan vigorosamente fuerzas corrosivas, tanto internas como externamente: el pluralismo político y social interno, que se opone a la idea misma de soberanía y de sujeción; la formación de centros de poder alternativos y concurrentes con el Estado, que operan en el campo político, económico, cultural y religioso, con frecuencia en dimensiones totalmente independientes del territorio estatal; la progresiva institucionalización, promovida a veces por los propios Estados, de 'contextos' que integran sus poderes en dimensiones supraestatales, sustrayéndolos así a las disponibilidad de los Estados particulares; e incluso la atribución de derechos a los individuos, que pueden hacerlos valer ante jurisdicciones internacionales frente a los Estados a los que pertenecen (2004: 8).

Por su parte, la propuesta de federalismo pluralista de Miquel Caminal, cuya tesis central es la separación del federalismo político de los nacionalismos estatales, aboga por una constitucionalidad sobre la base de una cultura federal, que permita desarrollar y profundizar la democracia:

[...] La razón positiva del federalismo frente al nacionalismo es que puede promover el pluralismo en varias dimensiones: policentrismos frente al monocentrismo, plurinacionalidad frente a la nacionalidad única, multiculturalismo frente al monoculturalismo. [...] La razón federal negativa, que defiende el espacio de libertad, de seguridad y de gobierno ante y junto al otro, y la razón federal positiva, que promueve la participación política y la interrelación cooperante y solidaria entre los diversos actores políticos vinculados por el pacto federal, son los pilares de un federalismo republicano y pluralista como vía de continuidad y cambio de las actuales democracias liberales en el proceso de profundización de la democracia (Caminal, 2002: 156).

Sin embargo, al contextualizar estas propuestas de Serrano y Caminal, particularmente la del último, en el caso de México y sus entidades federativas, y recuperar el análisis de las situaciones de hecho, resulta imposible obviar que el federalismo enfrenta problemas primarios reales insoslayables en tanto constituyen condiciones para pensar en una estructura constitucional que se desplaza al campo de la cultura y a la renovación de valores democráticos, como los de libertad, justicia e igualdad.

Coincidimos con el diagnóstico de la CERE cuando afirma que el proceso de federalización ha carecido de una estrategia coherente y, en síntesis, se reconoce la ausencia de un Estado auténticamente federalista capaz de generar la prosperidad conjunta de todos los miembros federados, razón por la cual hoy se reconocen tres méxicos. Chiapas es, por supuesto, representativo del México que tiene los mayores índices de desigualdad y subdesarrollo económico, social y político (García y Villafuerte, 2001). El mayor desafío de la reforma del Estado es romper con esas asimetrías, que implican convertir al federalismo en una política de Estado que, como señala la Comisión, dé coherencia al proceso de distribución del poder público de la Federación a los estados y municipios. ${ }^{8}$

Mientras esto no ocurra, para la sociedad chiapaneca más que para sus gobiernos, el problema de la distribución social y territorial inequitativa de la riqueza nacional continúa siendo una deuda que no ha sido encarada por la transición democrática, por lo que se refuerza la percepción de que no se resolverá sólo por la vía electoral. En el plano individual y colectivo, la recurrente desprotección social por la desigual distribución del ingreso inhibe el desarrollo real de una ciudadanía capaz de ejercer un papel responsable y autónomo en la toma de decisiones del campo gubernativo local (Lomnitz, 2000). Hablamos aquí de 
situaciones de hecho, de tensiones que se dan entre la democratización política y la vida cotidiana de sectores sociales mayoritarios que viven profundos procesos de exclusión y subalternidad. El problema en el espacio local no es sólo identificar el carácter negativo y regresivo que para los procesos de democratización ejercen las prácticas formales e informales generadas por la exclusión de las mayorías, en tanto producen disposiciones sobre las formas de percibir, hacery pensar lo político, sino cómo neutralizar dichos efectos, generando un campo de fuerzas que defina una correlación favorable en la reconstrucción de una ciudadanía hoy frágil y debilitada. ${ }^{9}$ Se trata de una tarea difícil por la poca luz que ilumina el camino pero, como bien recuerda Norberto Bobbio (2000), es una tarea que hay que asumir porque el camino se torna común.

Para terminar este apartado se impone reflexionar sobre uno de los centros gubernativos estratégicos para conocer las formas de los procesos de cambio político en espacios periféricos: el municipio. Como la expresión más pequeña y formal del gobierno local, no nos cabe duda del papel estratégico que está llamado a jugar el municipio y su gobierno. No es un hecho menor la injerencia directa del Banco Mundial, BM, o el Banco Interamericano de Desarrollo, BID, en el diseño de estrategias de modernización de la administración pública municipal cuya legitimidad estaría dada en un proceso continuo de "rendición de cuentas" en la que ahora se involucran a las organizaciones de la sociedad civil (World Bank, 1991). Tampoco, la preocupación de los gobiernos, federal y estatal, articulados a estos organismos, por impulsar estrategias municipalistas de modernización gerencial y política promoviendo la participación activa de la sociedad local.

Es cierto que las preocupaciones por los gobiernos locales sugieren la búsqueda de estrategias para definir al municipio como 'institución gubernativa nodal' que establece relaciones cara a cara entre gobernantes y gobernados, y recupera de los valores de la sociedad civil y la ciudadanía en la constitución de gobiernos locales democráticos y sustentables. Los gobiernos locales democráticos serán así el producto de un juego electoral competitivo bajo reglas previamente definidas que posibilitan la pluralidad política, amplios márgenes de gobernabilidad y el respeto a las preferencias de las mayorías. A este sustento de elección legítima, le precede un ejercicio gubernativo eficiente, el otro atributo insustituible de la gobernabilidad. Apoyado en el manejo eficaz de los recursos y en la incorporación de la sociedad local como corresponsable en el diseño y la práctica de las políticas públicas, el buen gobierno local encara idealmente objetivos inéditos: mejoramiento de la calidad de vida de la población, inclusión de la equidad como estrategia de corrección política — political correct-, y vigilancia o demanda por un manejo transparente de la hacienda municipal — accountability - entre otros.

Sin dejar de reconocer la validez de estos postulados gubernativos, sostenemos que el éxito a mediano y largo plazo de estos esfuerzos gerenciales en los ámbitos municipales, sólo parece estar garantizado en los municipios urbanos que poseen los niveles más altos de desarrollo socioeconómico y político del país, mientras que en municipios con menores grados de desarrollo será excepcional. En particular, éste no es el caso de la mayoría de los municipios de Chiapas ni del país. Desde una perspectiva funcional y optimista puede sostenerse como posible que las estrategias y los lineamientos de diseño político-administrativo, permitan, en un número significativo de municipios rurales, superar los bajos índices de profesionalización y tecnificación que caracterizan a las administraciones municipales; que la sociedad local se interese, en algún grado, por los problemas y las soluciones definidas en la esfera de los gobiernos locales. Sin embargo, como ocurre con el proceso democrático, estos diseños y su despliegue real tendrán impactos positivos sumamente frágiles si no se realizan cambios sustantivos en las áreas estratégicas del sistema federal orientados a encarar las 
desigualdades y las profundas asimetrías que en materia de desarrollo socioeconómico, político y cultural caracterizan al territorio y a la sociedad nacional. El debate de fondo es sobre el equilibrio de competencias y recursos o participaciones, siempre complementarios, entre poderes e instancias de gobierno.

La mayoría de los gobiernos municipales de Chiapas y del país enfrentan un entorno profundamente asimétrico en la distribución de los ingresos públicos, sin posibilidades reales de revertirlo (Martínez Uriarte, 1996). Con una recaudación precaria y con recursos insuficientes para "superar la pobreza" es prácticamente imposible pensar en la instauración real de relaciones sustentables de gobernabilidad; al contrario, las disputas por los escasos recursos vulneran incluso los sustentos mínimos de ésta. ${ }^{10}$ En relación con la hacienda municipal del país, Guerrero (2000) registra que las participaciones, en las que el municipio tiene una influencia marginal, representan prácticamente la mitad de los ingresos totales municipales en el ámbito nacional. No obstante, para tres de cada cuatro municipios del país, las Participaciones representan más de $90 \%$ de sus ingresos y apenas alcanzan a cubrir el gasto corriente de los municipios. ${ }^{11}$

La otra fuente de recursos ordinarios indirectos son las transferencias que provienen del Ramo XXVI; recursos, que con su descentralización en 1995, están llamados a convertirse en la principal fuente para el financiamiento de obra pública de los gobiernos locales. Sin embargo, señala Guerrero (2000), los problemas siguen siendo casi los mismos que con las Participaciones: la incertidumbre en los flujos de los recursos, su insuficiencia para encarar las necesidades locales reales y la discrecionalidad en la asignación, vigilancia y control de estos recursos asignados para el combate a la pobreza. ${ }^{12}$

Las finanzas municipales, que son los recursos directos, registran un monto que no sólo es marginal para la mayoría de los municipios del país, sino que también presentan límites estructurales para generarlos. A este respecto, Guerrero de nuevo señala que la municipalización de los Impuestos sólo beneficia a los municipios con grados elevados de urbanización por encima de cincuenta mil habitantes-, en donde destacan municipios de once entidades federativas, los cuales en 1991 generaron más de $85 \%$ de los recursos que se recaudaron por predial en el país. ${ }^{13}$ Los otros impuestos, además de marginales, siguen un comportamiento similar al impuesto predial; esto es, tienen importancia para los municipios mayormente urbanizados. Ocurre lo mismo con los demás recursos directos, Derechos — servicios del agua potable y alumbrado público- - y Aprovechamientos - multas, rezagos, reintegros-, que son importantes y en un futuro inmediato auguran constituirse en fuentes decisivas para el fortalecimiento hacendario de aquellos municipios urbanizados; en la mayoría de los municipios, prácticamente rurales, estos servicios sólo existen parcialmente, o las formas de prestación de los mismos operan a través de convenios con el Estado, en donde se incluye el subsidio.

Romper con las profundas asimetrías que caracterizan a las entidades federativas y sus municipios en materia de desarrollo económico y hacer menos drásticas las desigualdades socioeconómicas de la sociedad nacional siguen siendo, quiérase o no, los desafíos más grandes del país, y exigen compromisos de largo aliento por parte de los diversos actores que ponen en juego sus intereses políticos y económicos inmediatos. Dada la trivialidad y el voluntarismo manifiesto en los acuerdos o pactos entre los actores políticos y sociales, dichos compromisos deberían traducirse en una política de Estado y en la efectividad cotidiana de los derechos y obligaciones del ciudadano, contenidos en la Carta Magna. Con esto último, particularmente con los derechos sociales universales, se estaría no sólo quitando el oxígeno a la práctica clientelar y populista, dos de los grandes males de la 
cultura política mexicana, se estarían creando de igual modo condiciones efectivas para el desarrollo de una ciudadanía activa, participativa y responsable.

En Chiapas, la ciudadanía autónoma, participativa y deliberativa en la esfera de lo público es apenas un desafío de construcción social; de forma similar, pese a la prédica del colonialismo discursivo del Banco Mundial, la gobernabilidad, que tampoco se construye por decreto o buenos deseos, sigue siendo otro desafío de construcción sociopolítica, pues parafraseando a Alcántara al caracterizar la situación de los sistemas políticos en los países en desarrollo, el estado de Chiapas y la mayoría de sus municipios, al igual que todos los municipios pobres del país, están recurrentemente "al borde de una crisis de gobernabilidad" (Alcántara, 2004). Detrás de la estrategia discursiva que invoca la participación de la sociedad civil y la ciudadanía en el ejercicio gerencial y político del gobierno local, en aras de la legitimidad democrática y la eficiencia gubernativa local, está no sólo la preocupación por evitar situaciones de ingobernabilidad sino también el objetivo de potenciar los escasos recursos públicos que hoy se orientan a mal subsanar un problema que es, en sí mismo, de orden estructural.

La legitimidad del Estado mexicano y su régimen de gobierno federal exigen, sin excepción alguna, hacer realidad los derechos sociales del conjunto de los mexicanos, pues éste es el sery deber ser democrático. La definición de los términos de la redistribución de la riqueza nacional es esencialmente una definición de carácter político, y se legitima en los principios y sustentos normativos de una democracia constitucional (Stoker, 2000: 402). Ésta es una condición sine qua non o un imperativo del cambio político tendencialmente democrático para que genere justicia, desarrollo con integración social, mayores grados de institucionalización, consenso pluralista, reconocimiento y ejercicio pleno de derechos sociales, políticos, civiles y culturales.

\section{Cambiar para que todo siga igual. Lecciones de la primera alternancia en Chiapas}

En el año 2000 la sociedad chiapaneca, al igual que la nacional, registró una experiencia inédita de alternancia en el poder ejecutivo. Sin embargo, a pocos meses de concluir este primer ejercicio gubernativo, muchas de las expectativas y exigencias sociales se han erosionado con un alto costo político. La alternancia lejos de constituirse en el punto de partida de la transición democrática ${ }^{14}$ mostró los grandes desafíos que aún quedan por vencer. En el marco de una coyuntura donde el elemento central es la confrontación de las fuerzas políticas y sociales, las acciones que son propias de la alternancia, como la concertación para la definición normativa de los criterios de la representación política y la participación ciudadana, traducidas en una agenda amplia en la que se conjugan los intereses de las fuerzas políticas y sociales regionales y nacionales (Guillén, 1993), quedaron, desde el inicio del sexenio, descartadas.

La constatación en Chiapas del debate nacional abierto con la alternancia sobre cómo se produce la transición y la posibilidad de construir un sistema democrático estable, evidencia una serie de luces y sombras, discontinuidades y continuidades. Mismas que se pueden examinar en el campo de las relaciones intergubernamentales, la multiplicación de los conflictos por la recomposición del poder y el reposicionamiento de los actores sociopolíticos, las formas de relación entre el gobierno y la sociedad, así como precarios avances en la definición del papel del Estado y del liderazgo político en la construcción de una agenda propositiva para resolver las tensiones y los problemas que laceran las reformas. Particular énfasis debe hacerse en: a) las relaciones del ejecutivo con el congreso y los partidos de la entidad; b) el juego de pesos y contrapesos de poderes donde intervienen la prensa, los organismos empresariales ylas organizaciones sociales — corporativas 
o no-; c) la impartición de justicia en condiciones de pluralismo, la violación de los derechos humanos y el reconocimiento de los derechos ciudadanos; d) los problemas de representación, participación y las redes de fidelidades monopolizadas por la clase política chiapaneca y los cacicazgos regionales; e) la solución del conflicto armado, los enclaves autoritarios y los términos de la seguridad nacional.

Las relaciones entre los poderes ejecutivo y legislativo han sido definitorias de la trayectoria política seguida por el gobierno de la primera alternancia. De entrada, el gobernador electo inicia su administración sin la fuerza política de los partidos que conformaron la Alianzapor Chiapas en nombre de la cual llegó a la primera magistratura. ${ }^{15}$ Aunque la Alianza estructuró una plataforma política de convergencia, y registró ante el Consejo Estatal Electoral un convenio de coalición para postular un candidato común para la elección de gobernador, acordándose el reparto de su votación con base en los resultados de las elecciones inmediatas anteriores; en los hechos, frente al triunfo del candidato aliancista, los partidos que la formaron entraron en una conflictiva severa, no sólo por el cambio en la correlación de fuerzas que trajo consigo la modificación del voto del PRD y del PAN, sino por los términos desiguales de la integración al gobierno de la Alianza. El registro de políticos de origen priísta en el gabinete de primer nivel del gobierno y la declaración del gobernador de ser apartidista agravaron las tensiones, que derivaron en la desestructuración de la Alianza como tal.

El gobierno de la alternancia, con las particularidades del caso, se enfrentó a la experiencia de "un gobierno dividido". ${ }^{16}$ El ocho de diciembre de 2000 Pablo Salazar recibió el poder de manos de un Congreso estatal en donde la fracción perdedora, el PRI, detentaba la mayoría parlamentaria y con ello el control del poder legislativo. De un total de 40 diputaciones, 24 uninominales y 16 plurinominales, la fracción priísta tenía 26 curules. ${ }^{17}$ Una situación similar ocurrió con los gobiernos municipales en donde, de un total de 111 municipios, 85 eran administrados por el PRI. A ello se sumaron los resultados de las elecciones para la renovación de los diputados y senadores chiapanecos de la Cámara Alta y Baja del poder legislativo nacional en el mismo 2000, que fueron favorables al PRI. De un total de doce distritos, el PRI obtuvo once diputaciones de mayoría relativa, sólo perdió la diputación del distrito Ix con cabecera en Tuxtla Gutiérrez. Lo mismo ocurrió con las senadurías, en donde el triunfo correspondió al PRI, con excepción del distrito IX en donde triunfó el PRD. Esta composición legislativa, tanto local como federal, prácticamente se ha mantenido.

El rompimiento con la Alianza dejó al ejecutivo estatal sin el sustento formal de los partidos, ni siquiera el de los dos partidos más fuertes como el PRD y el PAN, lo que le restó posibilidades para, bajo las reglas del juego institucional, establecer en la arena legislativa una coalición formal que gobernara. Esta situación de vulnerabilidad llevó al ejecutivo estatal a definir una estrategia que tiende a la negociación individual y no con las fracciones parlamentarias como tales, ganándose las lealtades de diputados priistas en un número que hiciera posible el apoyo legislativo favorable a sus iniciativas y propuestas. Esta estrategia terminó desplazándose a los campos de las relaciones entre el ejecutivo estatal y las organizaciones campesinas y los gremios empresariales y sindicales.

La alternancia fue así secuestrada por una coyuntura política de confrontaciones cuyas salidas derivaron en el uso de estrategias con recursos no democráticos. Ello terminó colocando al ejecutivo estatal en una situación de fragilidad ante la sociedad, en tanto que ésta registra que se repiten los viejos esquemas, donde los consensos parlamentarios terminan generándose fuera de las instituciones y sus marcos normativos. El descrédito del poder legislativo local ha sido aún mayor. No es una exageración decir que vive su peor etapa y prácticamente está imposibilitado para asumir los retos 
del ajuste y de las reformas que exigen un proceso de transición política de naturaleza democrática. Dicho proceso empieza por la recuperación de su autonomía frente al poder ejecutivo, y con ello de su liderazgo, no sólo para reformar, en atención a las nuevas exigencias, su estructura normativa, particularmente en lo referente a los mecanismos de decisión interna, sino para impulsar la democratización de los otros poderes y de las otras instituciones políticas. Las fracciones parlamentarias no reflejan ningún interés por asumir los retos de la transición y la correlación de fuerzas apuntala a una mayor debilidad del Congreso local.

Desde este escenario, tampoco es de extrañar la ausencia de un liderazgo en la construcción de la agenda y las propuestas de una reforma del Estado mexicano desde la periferia chiapaneca. Frente a la aprobación por parte del Congreso de la Unión de una reforma Constitucional en materia indígena, contraria a los Acuerdos de San Andrés, que derivó en el rompimiento de relaciones del EZLN con el gobierno federal, y no obstante el voto en contra de dicha reforma por parte del congreso estatal, éste ya no insistió en la conveniencia de hacer posible la última reforma en el territorio estatal: ${ }^{18}$ el escenario militar y político y la ruptura del EZLN con el gobierno federal prácticamente imposibilitó debatir tal propuesta, no obstante el comportamiento discreto del actual Ejecutivo estatal hacia el grupo rebelde. A poco más de un año de terminar el periodo de gobierno no se ha cumplido la promesa, dicha a raíz de la aprobación de la Ley Indígena en las instancias federales, de promover una Ley Estatal más cercana a los intereses de los indígenas y de sus representantes. De hecho, de esta manera se deja pendiente o de lado toda la agenda política que supondría la solución jurídica del problema de la paz y, con ello, la posibilidad de un real y efectivo pacto democrático.

Si la agenda planteada no ha sido objeto de debate entre el EZLN y el gobierno federal y sus temas centrales mucho menos resueltos durante el gobierno de la alternancia, tampoco se ha dado, como contraparte, un liderazgo en la discusión sobre los términos de las propuestas legislativas en el campo de la reforma del Estado mexicano. Las iniciativas constitucionales y las propuestas políticas instituidas en el plano nacional han sido aprobadas por el congreso local sin hacer ningún esfuerzo por adaptarlas al perfil de los municipios chiapanecos. Este comportamiento lo documenta Rodríguez (2004), con la reforma del artículo 115 de la Constitución de los Estados Unidos Mexicanos, la cual fue aprobada por la Lx Legislatura del Congreso estatal, tres meses después del plazo previsto para realizarla. ${ }^{19}$ Las limitadas adecuaciones insertas en la constitución local cancelaron la posibilidad de estructurar, debatir y llegar a consensos sobre los grandes problemas que definen la agenda municipalista chiapaneca.

En lo que respecta a los partidos políticos y sus relaciones con el poder ejecutivo, permanecen marcadas por la lógica manifiesta en el comportamiento de sus respectivas fracciones parlamentarias y por el abierto pragmatismo que guarda su comportamiento frente al poder gubernativo. Los partidos políticos en Chiapas, que enfrentan una necesidad de cambios reales en sus estructuras internas de decisiones para propiciar la unidad y un nuevo marco de relaciones con sus afiliados y con la sociedad a la que aspiran gobernar, están prácticamente imposibilitados para asumir el liderazgo de una transición política de orientación democrática. Las diferencias internas y la desarticulación con la sociedad regional y sus problemas y aspiraciones han terminado por seguir oxigenando una estructura política en donde los mecanismos de decisión siguen dándose en las cúpulas nacionales y en las lealtades que los dirigentes estatales establecen con las dirigencias del centro del país. La orfandad de militantes reales y activos los ha llevado a menospreciar la construcción, y su revisión crítica y continua, de una plataforma política como expresión de un proyecto político sostenido en 
el tiempo. Ello ha propiciado un campo abierto de negociaciones en el que las coaliciones y las candidaturas se dan y se ofrecen al mejor postor, sin que éste registre experiencia alguna en el partido o la coalición que lo ha nominado como candidato a un puesto de elección popular.

En esta experiencia gubernativa, el juego de pesos y contrapesos de poderes donde intervienen los actores económicos y sociales, como la prensa, los organismos empresariales y las organizaciones populares y de ámbitos civiles más restringidos, ha sido sumamente desbalanceado y restrictivo. La prensa ha enfrentado serias tensiones con el Ejecutivo estatal, mismas que culminaron con la reforma del Código Penal del Estado, conforme al cual los delitos contra el honor pasan de tres a nueve años de prisión, ${ }^{20}$ hecho que conminó a periodistas locales a la movilización y a la búsqueda de las instancias internas e internacionales para evitar la vigencia de dicha reforma; ${ }^{21}$ los organismos empresariales chiapanecos, dominados por una base de tradición agraria y acostumbrada a velar por sus intereses particulares, mantienen poco interés por contribuir e impulsar las tareas de la transición democrática. ${ }^{22}$ Respecto a las relaciones entre las organizaciones sociales y el poder gubernativo la situación es más crítica y compleja. Por ejemplo, basta mencionar las tensiones con los sindicatos de la educación y de la salud que condujeron a plantones, huelgas y manifestaciones a los que las autoridades respondieron con estrategias de "prueba de fuerza".

Las organizaciones populares no sólo han enfrentado la dislocación de los organismos corporativos del otrora partido dominante, el PRI, y el resquebrajamiento de los organismos gubernamentales, responsables de las políticas de fomento al desarrollo agropecuario, que por décadas aportaron recursos y servicios que sustentaron el trabajo de estas agrupaciones, sino también la instrumentación de políticas sectoriales que prácticamente los deja al margen del manejo y la operación de las mencionadas. Los efectos más visibles han sido la continua fragmentación y confrontación, situación que convierte a sus líderes en presa fácil de estrategias soterradas de clientelismo y faccionalismo político por parte de actores políticos y económicos locales o regionales. El hecho visible es la "compra" de algunos de sus dirigentes a cambio de lealtades que corrompen las aspiraciones genuinas de sus bases.

\section{Conclusiones}

La reforma del Estado, una tarea que auguraba tener éxito dado el contexto de alternancia política con el que se iniciaba el siglo XXI, sigue siendo una asignación pendiente. Lo es aún más en las entidades federativas, sobre todo en las periféricas que se caracterizan por su atraso socioeconómico, como lo es Chiapas. Aquí la tarea es todavía primaria, en tanto los cometidos de la alternancia fueron escasos o poco significativos. Más allá del escenario político que expresa luces y sombras de una democracia en ciernes, los desafíos democráticos que impulsan una reforma del Estado son enormes. Estos desafíos o retos podrían resumirse en relación con el papel de los actores, el desarrollo de la agenda política y el devenir del contexto de las acciones colectivas.

1. En la práctica ha sido visible la debilidad de los actores políticos - gobierno, legislatura local y partidos políticos - para asumir un liderazgo en los debates y propuestas en el campo de la reforma del Estado. La dinámica de confrontación entre los poderes ejecutivo y legislativo, entre partidos y entre éstos y el EZLN y la sociedad civil ha cancelado prácticamente la posibilidad de lazos horizontales para impulsar proyectos comunes. Puede afirmarse que muchos de los logros constitucionales alcanzados en el plano nacional — vistos desde el campo 
de las reformas del Estado- se han aprobado por el congreso local, sin una revisión crítica o esfuerzo por adaptarlos al perfil de la realidad del estado y sus municipios.

2. La agenda política que supondría la solución verdadera y definitiva del problema de la paz, y con ello la posibilidad de un real y efectivo pacto democrático, prácticamente se mantuvo intacta. Los temas centrales entre el EZLN y el gobierno federal no fueron objeto de debate ni resueltos durante el gobierno federal de la alternancia, tampoco en la instancia parlamentaria estatal.

3. En el contexto de la periferia y de las exigencias del mundo globalizado emergen voces subalternas con las demandas de los excluidos. Como conjunto, la acción colectiva ha facilitado la promoción de valores democráticos y el control de los abusos del poder, mediante su denuncia en la esfera pública. Este potencial social de transformación y cambio en la sociedad es alérgico al Estado aunque, paradójicamente, tampoco puede sustituirlo o prescindir de él o de los partidos políticos como instancias formalmente capaces de agregar los intereses de amplios sectores de la población. Se trata de un juego de dependencias recíprocas y contrapesos de poder.

Legitimar la democracia como valor y campo para dirimir y procesar los desequilibrios sociales generados por el orden económico imperante no ha sido una tarea menor. Tampoco el desafío de la transición que entraña no sólo la sincronía entre los cambios institucionales formales y los cambios de la sociedad civil, sino fundamentalmente la construcción de una ciudadanía autónoma que implica la interiorización y socialización, tanto en los espacios íntimos, cotidianos y privados, como públicos, de prácticas y valores democráticos. Por ello es que la transición reclama un encuadre institucional y una ciudadanía con capacidad de elección política y de definiciones estratégica en el proceso mismo de la transición (Jelin, 1996; Sojo, 1999). Sin alternancia no hay transición política, y sin ésta no hay reforma del Estado. Sin reforma del Estado no hay democracia.

El talón de Aquiles de Chiapas es la debilidad de la ciudadanía, y ésta obedece a la recurrente desprotección social (Lomnitz, 2000), un hecho que por fundamental paradójicamente lo damos por dado. La legitimidad del Estado mexicano y su régimen de gobierno federal exige, sin excepción alguna, hacer realidad los derechos sociales del conjunto de los mexicanos, pues esa es la esencia de la democracia política. Este reconocimiento, un deber ser democrático, choca con las exigencias de una economía neoliberal que opera al margen de un contexto en donde son visibles las profundas asimetrías regionales y las hondas desigualdades sociales.

La definición de los términos de la redistribución de la riqueza nacional es esencialmente una definición de carácter político, y se legitima en los principios y sustentos normativos de la democracia (Stoker, 2000: 402). La reforma del Estado, como hace tiempo lo reconoció Hernández (1996), debe "cortar de tajo" la concepción que sostiene a los derechos sociales como recompensa y asumirlos como una vía para construir ciudadanos y acercarlos a las instituciones y a la política, y viceversa.

\section{Notas}

${ }^{1}$ Compromisos para un Acuerdo Político Nacional, suscritos el 17 de enero de 1995 por los presidentes de los Comités ejecutivos nacionales del PRI, PAN, PRD y PT. El compromiso sustantivo fue la promoción del inicio del "diálogo nacional para la reforma política con la participación de todas las fuerzas políticas nacionales... El propósito de la reforma será 
profundizar las relaciones democráticas entre los poderes de la Unión y entre éstos y las órdenes de gobierno estatal y municipal, así como las relaciones entre las instituciones públicas, los partidos políticos y la sociedad civil" (Perfil de La Jornada, 18 de enero de 1995).

${ }^{2}$ La agenda fue elaborada y consensuada por los diputados y senadores del PRI, PAN, PRD y PT, que integraban la Comisión Legislativa de Diálogo y Conciliación para Chiapas. El texto Diálogo Nacional para la Reforma del Estado Mexicano establece cuatro temáticas: "La Reforma política. Nueva gobernabilidad democrática; México, país de leyes. La Reforma legal; La Reforma Económica; y La Reforma Social" (La Jornada, 28 de enero de 1995, p. 38).

${ }^{3}$ En la toma de protesta a su cargo, Vicente Fox planteó la necesidad de consensuar una nueva Constitución, ofreciendo siete reformas medulares: la de la consolidación de la democracia; la del combate a la pobreza e igualdad social; la educativa; la de crecimiento y estabilidad económica; la de la descentralización federalista; la de transparencia y rendimiento de cuentas, y la que abata la inseguridad y cancele la impunidad. Planteó que lograrla — la reforma del Estado_ - "nos obliga a ser audaces para romper paradigmas, inercias y atavismos, que han visto en el acuerdo un acto de capitulación, y en coincidencia política, prueba plena de cooptación" "“Inicia una nueva era", edición especial, ElFinanciero, 2 de diciembre de 2000, p. 7).

${ }^{4}$ A casi cinco años de la administración foxista, Porfirio Muñoz Ledo, coordinador de los trabajos de la CERE, reconoció en una entrevista que el presidente Fox, a pesar de haber hecho suya la reforma del Estado, no la recuperó durante su mandato. Afirmó: “Toda transición que no hace suya una reforma del Estado, que no construye instituciones, está condenada a descarrilarse. Y ahora es absolutamente claro; la falla puede ser histórica, al no haberse hecho a tiempo". "Usar la legalidad como arma política solamente y no como un aliento para reformar el Estado de Derecho para corregir y sancionar esos actos, me parece una perversión política” (El Financiero, 18 de marzo de 2004, p. 28).

${ }^{5}$ En septiembre del mismo año se firma un documento conjunto entre la COCOPA y la delegación del EZLN donde la primera se compromete a impulsar la participación del EZLN en el diálogo nacional para la reforma del Estado. Sin embargo, el poco interés que la parte gubernamental tenía por vincular al EZLN en el diálogo nacional es de alguna manera planteada por el senador Heberto Castillo, cuando se lamenta que en el paquete de reformas electorales aprobado por las Cámaras de diputados y senadores no se hubieran considerado las propuestas surgidas en la mesa de San Andrés Larráinzar.

${ }^{6}$ Otros avances, pero no el marco de los Acuerdos de San Andrés, fueron: la reforma al sistema jurídico de Chiapas (1995), la creación de la Secretaría para la Atención de los Pueblos Indios, y la Subprocuraduría de Justicia Indígena.

7 "La doctrina constitucional ha sabido distinguir como característica del Estado federal, la existencia de tres instancia de producción normativa y dos ámbitos territoriales de aplicación de esas normas: en primer término, lo que podríamos denominar el poder supremo nacional, indestructible [...] el genuino poder constituyente, que no es otro que el pueblo soberano [...]; en segundo lugar, el poder federal, constituido por los órganos del Estado federal; y, en último término, los poderes locales. A su vez, los ámbitos territoriales de validez de las normas producidas por estas tres instancias, corresponden a la totalidad del territorio nacional, en los dos primeros casos, y al ámbito geográfico de las partes integrantes del Estado federal, en el último" (Serrano, 2004: 8).

${ }^{8}$ La propuesta de la Comisión es la de "Construir un federalismo auténtico que reivindique el carácter libre y soberano de los estados de la federación como entidades creadoras del Pacto Federal. Un federalismo que reasigne facultades mediante los criterios de necesidades y capacidades locales: 1) reduciendo las facultades del Gobierno Federal para que los estados recuperen potestades, incluso las de índole tributaria; y 2) re-definiendo ámbitos y términos de concurrencia para que el Gobierno Federal conserve la función de establecer bases regulatorias y criterios generales.

Esta propuesta se concretaría mediante una revisión del régimen constitucional de distribución de competencias entre la Federación y los estados de la unión que deje incólume el principio por el cual quedan reservadas a los Estados aquellas facultades que no hayan sido conferidas de manera expresa a los poderes federales" (Muñoz Ledo, 2004: 214).

9 "[...] dado el hecho de que México aún tiene grandes masas de gente pobre con poca propiedad privada legal o empleo estable y legalmente sancionado, y dado también que el Estado mexicano todavía es incapaz de extender los derechos ciudadanos de manera universal, bien podemos ver la reemergencia de una dialéctica perniciosa entre el pueblo bueno y el pueblo malo" (Lomnitz, 2000: 149).

${ }^{10}$ A este respecto Martínez Uriarte (1996: 72) indica que mientras el sistema de participaciones fiscales premia la recaudación, los recursos del ramo xxvi tienen como objetivo "la 
superación de la pobreza", recursos que por supuesto no sólo resultan insuficientes, sino que también, dada la forma clientelar de su manejo, inhiben la participación ciudadana autónoma.

${ }^{11}$ Este autor señala que si bien las Participaciones son recursos que la Federación ofrece en forma incondicional, "los ayuntamientos no pueden hacer mucho más a título individual, que ir a la capital del estado cada mes a recoger su cheque de Participaciones, cuyo monto muchas veces desconocen. Es decir, que las acciones locales de la Tesorería municipal muy poco pueden influir los montos de las Participaciones" (Guerrero, 2000: 153).

${ }^{12}$ Desde 1997 los Municipios junto con los Consejos de Desarrollo Municipal pueden aprobar obras cuyo costo sea mayor de cien mil pesos. De acuerdo con el Programa para el Nuevo Federalismo, citado por el autor, desde ese año los gobiernos municipales ejercen directamente $65 \%$ del total de los recursos del Ramo 26, mientras que el 35\% restante es operado por los gobiernos de los Estados a través de los Convenios de Desarrollo Social. En 1997 se estimó que 80\% de las obras se ejecutaron con recursos del Fondo de Desarrollo Social Municipal (ibid:: 155).

${ }^{13}$ Estos son: Baja California, Chihuahua, Distrito Federal, Guanajuato, Jalisco, México, Nuevo León, Sinaloa, Sonora, Tamaulipas y Veracruz (ibid.: 157).

${ }^{14}$ Para Guillén (1993) la alternancia en los cargos de elección popular es el punto de partida de la transición democrática, entendiendo por ésta el "proceso de construcción de un nuevo espacio para la realización de la política, en donde la política electoral y sus componentes, fundamentalmente ciudadanos y partidos, reales y formales, constituyen el eje determinante para la integración y eventual funcionamiento de los aparatos de gobierno en todos sus niveles. La transición en este sentido [...] consiste en la superación de la relación orgánica entre el Estado y su partido oficial y, al mismo tiempo, en la superación de la política real -y decisiva- como atributo interno de este último, sobre todo, de la burocracia dirigente -incluyendo aquí al presidencialismo" (Guillén, 1993: 25-26). Según O’Donnell y Schmitter (1994) por transición se entiende: “el intervalo que se extiende entre un régimen político y otro. [...] Las transiciones están delimitadas, de un lado, por el inicio del proceso de disolución del régimen autoritario, y del otro, por el establecimiento de alguna forma de democracia, [...]." (1994: 19). Un índice del comienzo de la transición según estos autores es la liberalización; el otro es la democratización, entendiendo por esta última "aquellos procesos en que las normas y procedimientos de la ciudadanía son, o bien aplicados a instituciones políticas antes regidas por otros principios [...], o bien ampliados de modo de incluir a individuos que antes no gozaban de tales derechos y obligaciones [...] o para abarcar problemas e instituciones que antes no participaban de la vida ciudadana (íbid:: 22-23). ${ }^{15}$ Lo forman los siguientes partidos: PRD, PAN, PT, PVEM y Convergencia por la Democracia, Partido del Centro Democrático, Partido de la Sociedad Nacionalista más el Partido Alianza Social. El 27 de mayo de 2000 Pablo Salazar Mendiguchía se registra como candidato de la Alianza por Chiapas.

16 "Se entiende por gobierno dividido aquél en el que, en el marco de un régimen de división de poderes, el partido llevó al presidente (o al gobernador) a ocupar la titularidad del Poder Ejecutivo aunque no cuente con el control mayoritario, esto es, con por lo menos 50\% + 1 de los escaños en la Asamblea legislativa —o en las dos cámaras, si se trata de un sistema bicameral" (Lujambio, 1996: 9).

${ }^{17}$ La fracción priista detenta 26 diputaciones, 23 de mayoría relativa y tres de mayoría proporcional; el PAN cinco diputaciones, una de mayoría relativa y cuatro de representación proporcional; el PRD tiene seis diputaciones plurinominales; el PT registra dos diputaciones de mayoría relativa, y una diputación de mayoría relativa el Partido del Frente Cívico.

${ }^{18}$ Debe reconocerse que el Congreso local votó en contra de la reforma que sobre derecho y cultura indígena habían aprobado los legisladores federales, decisión que fue posible por los oficios del ejecutivo estatal quien logró dividir a la fracción parlamentaria priista. Contra la oposición casi unánime del PAN; de un total de 35 diputados, 28 votaron en contra de la reforma, de éstos 19 fueron votos de diputados del PRI, seis del PRD, dos del PT y uno del Frente Cívico. De los seis diputados priístas restantes, cinco no se presentaron a la sesión y dos votaron a favor de la reforma.

${ }^{19}$ Se aprobó el 14 de junio de 2001.

${ }^{20}$ Se trata de las reformas al capítulo "delitos contra el honor". A decir del gobierno del Estado, los delitos contra el honor están catalogados como "no graves" y, por lo tanto, son sujetos del beneficio de la libertad caucional. Sin embargo, para el investigador Villanueva, "conmutar la pena privativa de libertad por la comisión de delitos contra el honor por fianza, ésta es tan alta que prácticamente ningún periodista podría pagarla" (véase Proceso, número 1438, 23 de mayo, 2004, p. 96). 
${ }^{21}$ Para Villanueva, “en México ningún código penal establece sanciones tan graves por ejercer la libertad de expresión o de información". Al respecto, señala: "Es evidente que penalizar $\mathrm{y}$, sobre todo, establecer sanciones privativas de la libertad física por expresar ideas e informaciones genera un efecto inhibitorio en los periodistas y acota, en consecuencia, el derecho de las personas a estar informadas. No se trata, por supuesto, de crear impunidad al quehacer periodístico, sino de comprender que el ejercicio del escrutinio de los asuntos públicos no puede ser tratado como si fuera un homicidio sin agravantes o un delito de lesiones, por poner dos ejemplos concretos” (2004: 61).

${ }^{22}$ Andrés Fábregas, antropólogo chiapaneco, recuerda la caracterización que su padre, un refugiado español, hizo de la clase económica chiapaneca, una definición tan vigente que vale recuperarla. El empresario chiapaneco, decía, "[...] es una clase dominante que viene de tradiciones agrarias, oligárquicas, y que ha pensado siempre no en cómo reproducir todo el contexto social, sino simplemente en cómo sobrevivir de la manera en que lo ha hecho siempre" (Molina, 1993: 121).

\section{Bibliografía}

Alcántara Sáez, Manuel, 2004, Gobernabilidad, crisis y cambio, Editorial FCE, México.

Aziz Nassif, Alberto (coord.), 2003, México al inicio del siglo XXI: democracia, ciudadanía y desarrollo, Grupo Editorial Miguel Ángel Porrúa/CIESAS, México.

Barros Horcasitas, Luis, Javier Hurtado y Germán Pérez Fernández del Castillo (comps.), Transición a la democraciay reforma del Estado en México, FLACso, Miguel Ángel Porrúa, México, pp. 75-86.

Bobbio, Norberto, 2000, El futuro de la democracia, Fondo de Cultura Económica, México.

Caminal, Miquel, 2002, El federalismo pluralista. Del federalismo nacional al federalismo plurinacional, Paidós, Barcelona.

Camou, Antonio (comp.), 2001, Los desafíos de la gobernabilidad, FLACSO / IISUNAM/ Plaza y Valdés, México.

Castells, Manuel, 1999, La era de la información. El poder de la identidad, Vol. II, Siglo xxI, México.

Cansino, César, 2004, El desafí democrático. La transformación del Estado en el México postautoritario, Cuadernos de Metapolítica, Centro de Estudios de Política Comparada, A. C., México.
Flores Olea, Víctor, 1995, "Partidos políticos y transición democrática”, Cemos Memoria, núm. 79, julio, pp. 5-9, México.

García Aguilar, María del Carmen y Daniel Villafuerte Solís, 2001, "Entre la pobreza estructural y la pobreza gestada por el neoliberalismo", en Jaime Castillo Palma, Elsa Patiño Tovar y Sergio Zermeño G., Pobreza y organizaciones de la sociedad civil, UAP/ CONACYT/ RnIU, México, pp. 19-54.

García Aguilar, María del Carmen, Xochitl Leyva Solano y Araceli Burguete Cal y Mayor, 1998, "Las organizaciones campesinas e indígenas de Chiapas frente a la reforma del Estado: una radiografía", Cuadernos Agrarios, número 16, Nueva Época, México, pp. 75-94.

Guerrero, Juan Pablo, 2000, "La hacienda municipal en México", Ciudadania, poder politico y gobierno, $2^{\circ}$ Congreso RNIU: Investigación Urbana y Regional Balance y Perspectivas, Universidad Autónoma de Puebla/ Red de Investigación Urbana, A. C., México, pp.152-172.

Guillén López, Tonatiuh, 1993, Baja California 1989-1992. Alternancia Politica y Transición Democrática, El Colegio de la Frontera Norte y Centro de Investigaciones Interdisciplinarias en Humanidades, unAm, México.

Guillén, Tonatiuh y Alicia Ziccardi (coords.), 2004, Innovacióny continuidad del municipio mexicano. Análisis de la reforma municipal de 13 estados de la República, H. Cámara de Diputados, LIX Legislatura, IIS- UNAM -Miguel Ángel Porrúa, México.

—, 1996, "Gobierno Dividido en Baja California: introducción y dinámica legislativa en el periodo 1989-1995”, en Alonso Lujambio (ed.), Poder Legislativo. Gobiernos Divididos en la Federación Mexicana, UAM-IFE -Congreso Nacional de Ciencias Políticas y Administración Pública, México.

Hernández Chávez, Alicia, 1996, "Federalismo y gobernabilidad en México", en Marcelo Carmagnani (coordinador), Federalismos Latinoaméricanos: México, Brasil, Argentina, FCEEl Colegio de México, México, pp. 263-299.

Jelin, Elizabeth, 1996, "La construcción de la ciudadanía: entre la solidaridad y la responsabilidad", en Elizabeth Jelin y Eric Hershberg (coords.), Construir la democracia: derechos bumanos, ciudadanía y sociedad en América Latina, editorial Nueva sociedad, Venezuela, pp. 113-130.

Krasner, Stephen D., 2001, Soberanía, hipocresía organizada, Paidós, Barcelona.

Lomnitz, Claudio, 2000, "La construcción de la ciudadanía en México”, Metapolítica, volumen 4, julio/ septiembre, 2000, México, pp. 128-149. 
Lujambio, Alonso, 1996, "Estudio Introductorio", en Alonso Lujambio (ed.), Poder Legislativo. Gobiernos Divididos en la Federación Mexicana, UAM-IFE-Congreso Nacional de Ciencias Políticas y Administración Pública, México, pp. 9-31.

Martínez Uriarte, Jacqueline, 1996, "Las participaciones fiscales como agentes de recursos para los municipios", en Jacqueline Martínez Uriarte y Alberto Díaz Cayeros (coords.), Federalismo, Congreso Nacional de Ciencia Política, uAm/ IFE/ Colegio Nacional de Ciencias Políticas y Administración Pública, México, pp. 63-80.

Molina Hurtado, María Mercedes, 1993, En tierra bien distante. Refugiados españoles en Chiapas, Gobierno del Estado de Chiapas, Consejo Estatal de Fomento a la Investigación de la Cultura, DIF-Chiapas, Instituto Chiapaneco de Cultura, México.

Muñoz Ledo, Porfirio (coord.), 2004, Comisión de Estudios para la Reforma del Estado. Conclusiones y propuestas, unAM, México.

O’Donell, Guillermo y Schmitter, C. Philippe, 1994, Transiciones desde un gobierno autoritario, Paidós, España.

Pérez Fernández del Castillo, Germán, 2001, "La reforma del Estado en México. Una revisión crítica", en Antonio Camou (comp.), Los desafíos de la gobernabilidad, FLACso/ issunam / Plaza y Valdés, México, pp. 211-240.

Requejo, Ferrán, 2002, "Un federalismo para primates... que pugnan por dejar de serlo", en Miquel Caminal, El federalismo pluralista. Del federalismo nacional al federalismo plurinacional, Paidós, Barcelona, pp. 11-31.

Rodríguez Wallenius, Carlos A., 2004, "Análisis de una reforma limitada. Los cambios constitucionales en materia municipal en Chiapas", en Tonatiuh Guillén y Alicia Ziccardi (coords.), Innovación y continuidad del municipio mexicano. Análisis de la reforma municipal de 13 estados de la
República, H. Cámara de Diputados, LIX Legislatura, IISuNAM -Miguel Ángel Porrúa, México, pp. 515-535.

Serrano Medallón, Fernando, 2004, "El caos federal”, Este País, número 157, abril, México, pp. 6-10.

Sojo, Carlos, 1999, Democracia con fracturas. Gobernabilidad, reforma económica y transición en Centroamérica, FLACSO-Costa Rica, San José Costa Rica.

Stoker R., Robert, 2000, "Un marco de análisis para el régimen de implementación y cooperación de las políticas entre los imperativos federalistas", en Luis F. Aguilar Villanueva (ed.), La implementación de las políticas, Miguel Ángel Porrúa, México, pp. 373-412.

Torres, Juan Carlos, 1997, "El lanzamiento político de las reformas estructurales en América Latina", Politica y Gobierno, vol. IV, núm. 2, México, pp. 471-498.

Villanueva, Ernesto, 2004, "Delitos contra el honor", Proceso, número 1437, 16 de mayo, México, pp. 60-61.

Word Bank, 1991, Managing development: the governance dimension, Washintong, D.C., (mimeo).

\section{Información hemerográfica}

"Compromisos para un Acuerdo Político Nacional", La Jornada, 18 de enero de 1995, México.

"Diálogo Nacional para la Reforma del Estado", La Jornada, 28 de enero, 1995, México.

“1995-1997: Chiapas, esfuerzo compartido", Suplemento, Cuarto Poder, 7 de enero, 1998, Tuxtla Gutiérrez, Chiapas, México.

Proceso, número 1438, 23 de mayo, 2004, México.

ElFinanciero, 2 de diciembre de 2000, México.

ElFinanciero, 18 de marzo 2004, México. 